\title{
Assessing the effects of land use on biodiversity in the world's drylands and Mediterranean environments
}

\author{
Diego García-Vega ${ }^{1}$ (D) Tim Newbold ${ }^{1}$ (D)
}

Received: 30 January 2019 / Revised: 18 October 2019 / Accepted: 23 October 2019 /

Published online: 2 November 2019

(C) The Author(s) 2019

\begin{abstract}
Biodiversity models make an important contribution to our understanding of global biodiversity changes. The effects of different land uses vary across ecosystem types, yet most broad-scale models have failed to account for this variation. The effects of land use may be different in systems characterized by low water availability because of the unusual conditions within these systems. Drylands are expanding, currently occupying over $40 \%$ of the terrestrial land, while Mediterranean systems are highly endangered biodiversity hotspots. However, the impact of land use on biodiversity in these biomes is yet to be assessed. Using a database of local biodiversity surveys, we assess the effects of land use on biodiversity in the world's drylands and Mediterranean ecosystems. We compare the average species richness, total abundance, species diversity, ecological dominance, endemism rates, and compositional turnover across different land uses. In drylands, there was a strong turnover in species composition in disturbed land uses compared with undisturbed natural habitat (primary vegetation), but other measures of biodiversity did not respond significantly. However, it is important to note that the sample size for drylands was very low, a gap which should be filled promptly. Mediterranean environments showed a very high sensitivity of biodiversity to land uses. In this biome, even habitat recovering after past disturbance (secondary vegetation) had substantially reduced biodiversity and altered community composition compared with primary vegetation. In an effort to maintain original biodiversity and the ecosystem functions it supports within Mediterranean biomes, conservation measures should therefore prioritize the preservation of remaining primary vegetation.
\end{abstract}

Keywords Biodiversity $\cdot$ Drylands $\cdot$ Land use $\cdot$ Mediterranean $\cdot$ Synthetic model

Communicated by Daniel Sanchez Mata.

Electronic supplementary material The online version of this article (https://doi.org/10.1007/s1053 1-019-01888-4) contains supplementary material, which is available to authorized users.

Diego García-Vega

diegogavega@gmail.com

Tim Newbold

t.newbold@ucl.ac.uk

1 Centre for Biodiversity and Environment Research, Department of Genetics, Evolution and Environment, University College London, Gower Street, London WC1E 6BT, UK 


\section{Introduction}

The rate of global biodiversity loss has accelerated rapidly in the past century as the rate of human activities has also accelerated (Ceballos et al. 2015; Steffen et al. 2015). Habitat loss has been the main driver of this decline worldwide, and is responsible for nearly two thirds of the terrestrial surface having transgressed a proposed 'safe limit' of local species extinctions (Newbold et al. 2016a). More than three quarters of the Earth's ice-free land area has been modified or is under use by humans to some extent (Ellis and Ramankutty 2008). A major contributor to human land use is agricultural production, with an estimated $37 \%$ of the terrestrial surface converted to agriculture by 2015 (The World Bank 2017). Human land uses, including agricultural lands, urban areas and plantation forests, are predicted to further expand in the coming decades to meet the rising demand of a growing population (Seto et al. 2011; Kröger 2014; Von Lampe et al. 2014). How landscapes evolve around the world in the near future will determine the rates of biodiversity loss, and understanding the impacts of land use is therefore central to the conservation of biodiversity.

Declines in biodiversity negatively affect local ecosystem functions and services, and thus are a major threat for humanity (Cardinale et al. 2012). Plant and animal biodiversity are positively linked to plant productivity and soil health (Lal 2004; Maestre et al. 2012), and thus may enhance the sequestration of atmospheric carbon (Lal 2004). The loss of diversity may consequently slow down the mitigation of $\mathrm{CO}_{2}$ levels and undermine progress on limiting climate change. Additionally, increased crop yields and resilience to perturbations are associated with higher species diversity within agricultural lands (Di Falco 2012). Biodiversity conservation may therefore play an important role in securing food availability in the face of a growing demand and changing environmental conditions.

The effects of land use on non-cultivated biodiversity are variable across ecosystem types. Previous studies have found widely differing effects of land use in different biomes. For instance, agricultural fields reduce numbers of species and individuals in tropical forests (Newbold et al. 2014), but may increase them in deserts (e.g. McIntyre et al. 2001; Norfolk et al. 2015). Most models of the response of biodiversity to land use assume a single relationship for all biomes/ecosystem types (e.g. Sala et al. 2000; Newbold et al. 2015), thus failing to distinguish spatial differences in responses. Another issue is that many biodiversity models use relatively simple measures of biodiversity, such as numbers of species or individuals (Newbold et al. 2014), which can be inadequate for fully representing biodiversity changes (Hillebrand et al. 2018). Considering changes in the species composition of communities is also informative (Dornelas et al. 2014; Newbold et al. 2015, 2016b, 2018). Globally, land use has been shown to cause a replacement of more endemic with more wide-ranging wild species (Newbold et al. 2018).

Drylands and Mediterranean biomes are characterized by relatively low rainfall, which may lead to unusual responses of biodiversity to land use. It is estimated that land use has been responsible for both drylands and Mediterranean environments being among the biomes to have experienced the largest declines in biodiversity to date (Newbold et al. 2016a), but without accounting for potential differences in land-use responses in these biomes compared to other environments. Further, projections rank Mediterranean as the biome that will face the largest loss of diversity in the coming years, with land use being the strongest driver of these declines (Sala et al. 2000). Mediterranean environments are additionally threatened by land degradation and desertification, induced by further human land-use changes and increasingly warm and dry conditions (Geeson et al. 2002). Drylands have also witnessed a large historical decline in species diversity and abundance as a result 
of human land uses (Newbold et al. 2016a), and land-use impacts on biodiversity are predicted to become greater in hot and dry places (Mantyka-Pringle et al. 2012); yet further land conversion is expected to be moderate in this biome (Sala et al. 2000).

While most broad-scale models have failed to recognize that responses vary among ecosystem types, there have been a few regional and many local studies on the impact of land use in Mediterranean and dryland environments (indeed, the database we use here is a collation of such local studies). For example, at regional scales, land-use changes in Mediterranean environments in Italy have been associated with losses of Mediterranean-specialist species (Falcucci et al. 2007). Similarly, livestock grazing in Australia (which is comprised mostly of dryland or Mediterranean ecosystems) is associated with reductions in plant biomass and abundance, and to a lesser extent animal species richness (Eldridge et al. 2015). In drylands, small-scale studies of the effects of arable agriculture and livestock grazing on local biodiversity have found generally weaker and sometimes positive effects, which differ strongly among taxonomic groups (Milchunas et al. 1998; McIntyre et al. 2001; Norfolk et al. 2013, 2015). On the other hand, dryland studies have also shown strong turnover in ecological community composition among land uses, at least for plant species (Norfolk et al. 2015).

We therefore expect different biodiversity responses between Mediterranean and dryland biomes. Owing to the increased productivity and water availability found in managed land uses compared to natural sites in drylands (Webb et al. 1978), species diversity and abundance may be higher. In contrast, by reducing the structural complexity of habitats, human alteration is expected to reduce the high diversity and abundance of Mediterranean habitats. Shifts in species communities across land uses are predicted in both biomes, with a replacement of more endemic species with more wide-ranging species, increasing the risk of local extinctions, and potentially leading to altered ecosystem functions (Symstad et al. 1998).

\section{Materials and methods}

\section{Study areas}

This paper analyses data from studies conducted across the world's drylands and Mediterranean ecosystems, as defined by the Nature Conservancy's (The Nature Conservancy 2009) map of ecoregions. Mediterranean biomes are characterised by hot and dry summers, followed by cool and moist winters that concentrate most of the annual rainfall (Olson et al. 2000). These ecosystems are significant biodiversity and endemism hotspots (Cowling et al. 1996; Myers et al. 2000), hosting 20\% of the Earth's plant species (Cody 1986). They are confined to around $2 \%$ of the terrestrial land area, distributed across 27 countries in five separate geographical regions (Fig. 1), and accounted for about $5 \%$ of the world's population in 2000 (Underwood et al. 2009). The Earth's drylands, on the other hand, are characterised by temperature extremes and by water scarcity, with evaporation rates usually equalling or exceeding rainfall (Olson et al. 2000). Drylands have diverse floral and faunal communities adapted to water scarcity, with high rates of species endemism (Olson et al. 2000). Expanding over 40\% of the Earth's terrestrial surface and at least 58 countries (Fig. 1), drylands are home to over $35 \%$ of the world's population (United Nations Environment Management Group 2011). Together, these two ecosystem types are therefore highly significant socio-ecologically. 


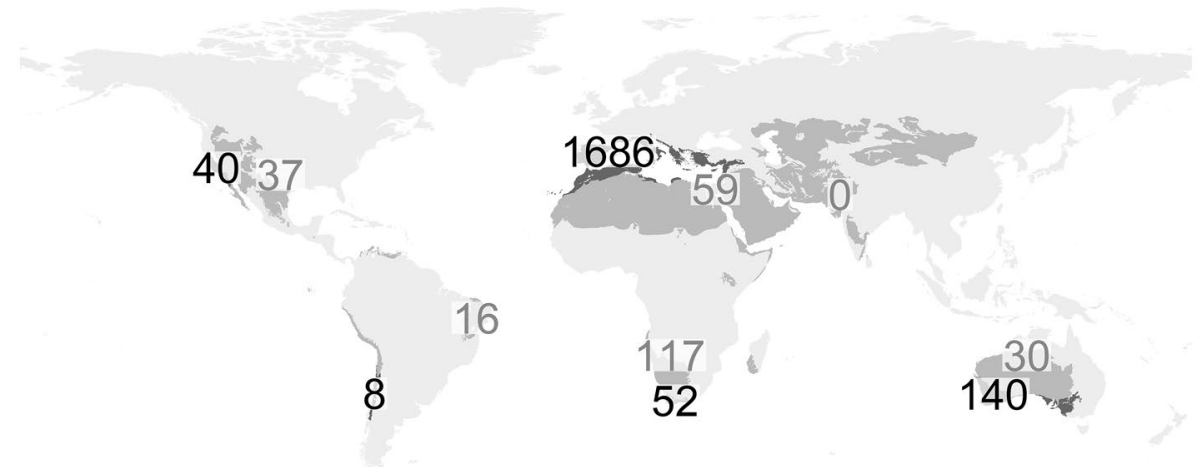

Fig. 1 Sites sampled in drylands and Mediterranean environments around the world. The light and dark grey shaded areas represent the distribution of dryland and Mediterranean biomes, respectively, based on The Nature Conservancy's (The Nature Conservancy 2009) ecoregions. Numbers represent the number of sites in each realm-biome combination: black text for Mediterranean sites and dark grey text for dryland sites

\section{The PREDICTS database}

Data were drawn mainly from the PREDICTS database (Hudson et al. 2016, 2017). The PREDICTS (Projecting Responses of Ecological Diversity In Changing Terrestrial Systems) Project has collated empirical data from local studies across the globe in every major type of ecosystem (Hudson et al. 2017), to build the most representative models of the effects of land use on biodiversity (Newbold et al. 2015). The PREDICTS database is a collation of studies comparing ecological communities across land uses, mostly published studies and surveys, with a few datasets from reports and databases published in the grey literature (Hudson et al. 2017). The database includes biodiversity surveys conducted in over 26,000 sites, with more than 47,000 species recorded (Hudson et al. 2016, 2017). Most studies in the PREDICTS database report the abundance of individual species, but a few report only species occurrence or in rare cases simply total community species richness. In all cases, studies gave site coordinates, and maintained constant sampling methods across sites (Hudson et al. 2014).

Since studies around the world have focused on a few taxonomic groups and biomes, there is an over-representation in the PREDICTS database of some regions over others, and of some taxonomic groups over others within these regions. Mediterranean biomes are well represented (1952 sites in around $2 \%$ of the terrestrial land area), while drylands are much less so (320 sites in over $40 \%$ of the land area). PREDICTS remains, nevertheless, one of the most complete databases currently available on biodiversity responses to land use across biomes. By analysing this wide collection of local data, assessments have been able to estimate broad-scale associations between diversity and land use, but the specific responses of biodiversity across habitats in drylands and Mediterranean biomes is yet to be assessed. In this study, we attempt to build as accurate and complete models as possible of land-use impacts on various different measures of biodiversity in drylands and Mediterranean environments.

Owing to the very low representation of drylands within the PREDICTS database, we supplemented the existing database with new data identified through a targeted search for studies of land-use impacts in drylands. To perform the targeted search, we used the 
keywords "diversity", "dryland", "arid", "desert", "land use", "agriculture", "cropland", "pasture", "urban", "plantation", "primary vegetation" and "secondary vegetation" in online search engines (Google Scholar, Web of Science). We found only two additional studies. Our search for additional datasets for drylands systems followed the same protocols used when compiling the original PREDICTS database (Hudson et al. 2014), although we didn't require the precise coordinates of sites.

\section{Mediterranean and dryland data}

The final dataset for Mediterranean environments included 179,701 records of species abundance or occurrence from 1926 sites, collated from 37 studies. The representation of drylands was much lower, including 17 studies with 18,761 records, from 320 sites. The fact that we conducted an extensive search for additional drylands data suggests that the limited representation of drylands likely reflects a limited number of studies in the primary literature rather than a systematic bias in the PREDICTS database.

Sites extended across every major area of the world where drylands and Mediterranean biomes occur (Fig. 1); yet some regions were more sampled than others. The vast majority of sites (1686) collated from Mediterranean environments were from the Palearctic realm, mainly from the Mediterranean Basin in Southern Europe, the largest area in the world with a Mediterranean climate. The least sampled area was South America, with eight sites. The sample sizes across the globe should be large enough to determine associations that are representative of the entire biome, assuming that Mediterranean biodiversity behaves similarly across continents (although studies have shown local variability within other ecosystems, such as tropical forests (e.g. Phillips et al. 2017).

In contrast, dryland sites covered a much smaller proportion of their total land area (Fig. 1). The most sampled region was sub-Saharan Africa (117 sites), and to a lesser degree North America (37 sites). In relation to their area, the Palearctic realm (including Northern Africa and the Middle East; 59 sites), Australasia (30 sites) and the Indo-Malay realm (no sites) were the least represented. Although the smaller total sample size of drylands may create a larger uncertainty in this biome's models, no significant geographical bias was present (apart from the absence of data for the Indo-Malay realm).

Land-use types in the database include primary vegetation (natural habitat with no record of prior destruction), secondary vegetation (natural habitat recovering after prior destruction by human actions or extreme natural events), croplands (areas used for growing herbaceous crops), pastures (areas used for livestock grazing), and plantation forests (areas used for growing woody crops, including several permanent crops that are important in Mediterranean regions such as olive and fruit trees) and urban habitats (areas of human settlement). Secondary vegetation sites at different succession stages (mature, intermediate, young or indeterminate age) and with different types of vegetation (forests, woodlands or scrublands) were clustered together in these analyses to increase their representation. Different secondary recovery stages and vegetation types were all represented in the sampled secondary vegetation sites (Supplementary Fig. 1, Table 2). Natural habitats, comprised of primary and secondary vegetation, were the most represented group in both biomes' datasets (Fig. 2). Agriculture constituted the second largest group of land uses, including pastures and croplands. While pastures were more abundant among the dryland agricultural sites, croplands were predominant among the Mediterranean sites. This may be to some extent a bias of the database, yet it also somewhat reflects the real overall share of these two land uses in each environment (Moore et al. 2010; The Food and Agriculture 

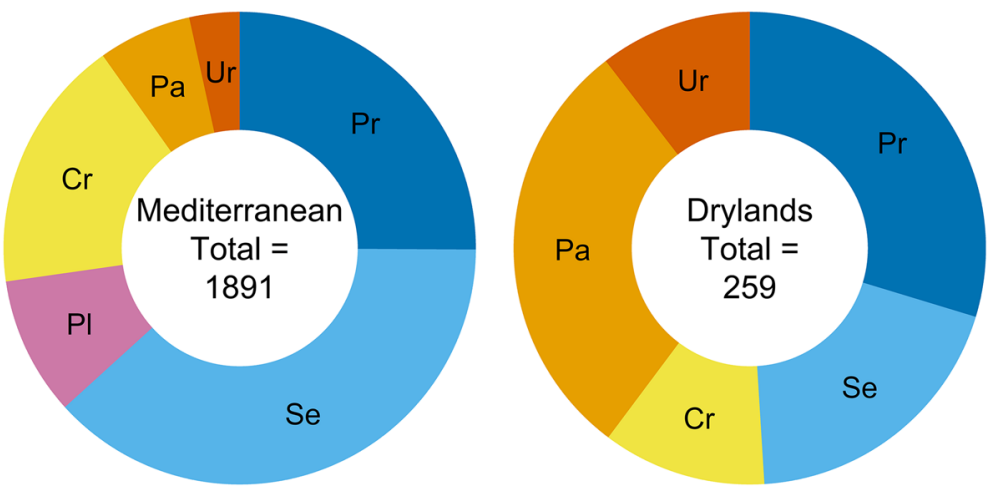

Fig. 2 Distribution of sites among land uses in drylands and Mediterranean environments. Numbers in the centre give the total number of sites within each biome. $\mathrm{Pr}=$ Primary Vegetation, $\mathrm{Se}=$ Secondary Vegetation, $\mathrm{Pl}=$ Plantation forest, $\mathrm{Cr}=$ Cropland, $\mathrm{Pa}=$ Pasture, $\mathrm{Ur}=\mathrm{Urban}$

Organization of the United Nations 2016). Urban sites and plantation forests were less sampled, particularly in drylands.

The database is composed of records for vertebrates, invertebrates, plants and fungi (Table 1). All four taxonomic groups are reasonably well represented in both biomes, except for fungi in drylands (with a total of only 3 sites), which are therefore excluded from this biome's analyses. Not all taxonomic groups are homogeneously represented across land uses (Table 1). The non-evenness of taxonomic groups across sites may create a certain bias in the model results.

Table 1 Number of sites in each land-use type within each of the studied biomes, in the final dataset used for analysis

\begin{tabular}{|c|c|c|c|c|c|c|c|}
\hline \multirow[t]{2}{*}{ Taxon } & \multicolumn{7}{|c|}{ Number of sites } \\
\hline & Primary & Secondary & $\begin{array}{l}\text { Plantation } \\
\text { forests }\end{array}$ & Croplands & Pastures & Urban & Total \\
\hline \multicolumn{8}{|l|}{ Drylands } \\
\hline Vertebrates & 45 & 10 & NA & 2 & 21 & 2 & 80 \\
\hline Invertebrates & 26 & 23 & NA & 27 & 15 & 16 & 107 \\
\hline Plants & 6 & 17 & NA & 0 & 40 & 9 & 72 \\
\hline Total & 77 & 50 & NA & 29 & 76 & 27 & 259 \\
\hline \multicolumn{8}{|l|}{ Mediterranean } \\
\hline Vertebrates & 107 & 222 & 78 & 259 & 21 & 0 & 687 \\
\hline Invertebrates & 93 & 166 & 24 & 35 & 22 & 35 & 375 \\
\hline Plants & 224 & 169 & 38 & 7 & 54 & 12 & 504 \\
\hline Fungi & 0 & 165 & 32 & 28 & 24 & 18 & 267 \\
\hline Multiple & 51 & 0 & 7 & 0 & 0 & 0 & 58 \\
\hline Total & 475 & 722 & 179 & 329 & 121 & 65 & 1891 \\
\hline
\end{tabular}

Sites are broken down by taxonomic group, with 'multiple' indicating sites where more than one of the taxonomic groups was sampled. Note that plantation forests and all sites sampled for fungi were not included in the drylands analysis because of insufficient representation 


\section{Species diversity, abundance and ecological dominance models}

Metrics and units of diversity, sampling methodologies and taxonomic groups sampled varied across studies. Owing to this hierarchical structure and non-independence of the data, we used generalized linear mixed-effects models (GLMMs) (Zuur et al. 2009). We included a random intercept of study identity to account for the expected large differences among studies. We also fitted a random intercept representing spatial blocks of sites within studies (see Hudson et al. 2014 for details), to account for the spatial structuring of sites. These hierarchically structured models are the best way to account for potential spatial autocorrelation in biodiversity measures short of fitting very complex models with spatial terms, which are computationally infeasible (Newbold et al. 2015). To test whether any spatial autocorrelation remained in the model residuals, we used a Moran's I test. All the statistical analyses were performed using the 'StatisticalModels' (https://github.com/timne wbold/StatisticalModels) and lme4 (v. 1.1-15) (Bates et al. 2015) packages in R (v. 3.3.2) (R Core Team 2016), using backward stepwise model selection, as recommended by Zuur et al. (2009). The significance threshold was set at 0.05. Studies that focused on a single species were excluded from the analysis.

We modelled the log-transformed total abundance of individuals, the Simpson's Reciprocal Diversity Index, and the Berger-Parker index as functions of land use in each biome, using a Gaussian distribution of errors. Being a list of integer count data, species richness was modelled using a Poisson distribution of errors, with site identity added as an additional random intercept to correct for over-dispersion (Rigby et al. 2008). The Simpson's reciprocal index offers a more complete look at diversity than species richness and total abundance alone, as it takes into account both species richness and abundance simultaneously. Moreover, this measurement is widely used and relatively independent of sample size (Somerfield et al. 2008), which makes it appropriate for the varying group sizes in this analysis. The Berger-Parker index measures ecological dominance, as the proportion of the entire community that is made up of the most common species. This measurement has been used successfully to assess changes in diversity between disturbed and undisturbed Mediterranean environments (Caruso et al. 2006).

Land uses may be distributed non-randomly with respect to climate, which in turn influences biodiversity, potentially biasing the results of the model. To control for this possibility, we included four climatic variables known to be important for biodiversity into our models: maximum temperature of the warmest month, minimum temperature of the coldest month, precipitation of the wettest month and precipitation of the driest month. We obtained all of these variables from WorldClim Version 1.4 at a spatial resolution of 30 arc-seconds (Hijmans et al. 2005), and intersected them with our site data using the 'raster' R package (v. 2.6-7) (Hijmans 2017). We removed any climatic variables that were highly correlated with others: maximum precipitation for the drylands models; and maximum temperature and maximum precipitation for the Mediterranean models.

\section{Endemism and species' identity}

In addition to broad changes in overall diversity levels across land uses, the species composition of communities may also shift (Newbold et al. 2016b), with geographically rare species typically disproportionately impacted by human land uses (Newbold et al. 2018). To test whether such compositional changes were occurring with land use in Mediterranean 
and dryland systems, we first calculated an inverse measure of community 'endemism' as an abundance-weighted average of the geographical range occupancy of all species within a community (Newbold et al. 2018). This measure has been shown to capture well differences in the way that narrow- and wide-ranging species respond to land use (Newbold et al. 2018). Each species range occupancy was defined as the total land area of $0.5^{\circ}$ grid cells occupied by records in the Global Biodiversity Information Facility (GBIF) (https://www. gbif.org/) (Newbold et al. 2018). We fitted community-average ( $\log _{10}$-transformed) range occupancy as a function of land use as before using GLMMs with a Gaussian distribution of errors. For these analyses, we grouped pastures and croplands to increase representation, and removed urban sites owing to their low representation. Owing to the potential nonrandom distribution of land uses with respect to climate, and the effect that climate may have on community-average range occupancy, we fitted the same climatic variables into the models as in the models of abundance, species richness and species diversity (see above).

To compare community composition between land uses, we created a species presence/ absence matrix for each site, where a species is absent in one site if it is not recorded in that site but is present in another site within the same study. We measured similarity between pairs of sites within studies using the Sørensen's index, which has been shown to capture well community turnover in simulated datasets (Boyce and Ellison 2001). Because this analysis required pairwise comparisons, and thus had a reduced sample size, the representation of drylands was particularly low. We excluded urban and plantation forest sites from both biomes' analyses due to the low sample size of compositional similarity data in these land uses. To increase their representation, we clustered agricultural land uses together for both biomes, as well as natural sites (primary and secondary vegetation) in drylands. We calculated the average similarity between each pair of land uses first within, and then across studies.

\section{Results}

\section{Summary}

Local diversity responded strongly and negatively to land use in Mediterranean environments worldwide (Figs. 3, 5). In contrast, no significant responses were detected in drylands, although diversity tended to be reduced in croplands (Fig. 4). Significant turnover in community composition was observed in both Mediterranean and dryland environments (Table 2).

\section{Abundance, diversity and ecological dominance models}

Abundance, species richness, Simpson's diversity index and dominance did not differ significantly across land uses in dryland environments (Likelihood ratio tests: all $\chi^{2<} 8.1$, $\mathrm{P}>0.09$; Fig. 4). Nevertheless, Simpson's diversity and species richness tended to be lower, and dominance tended to be higher in croplands. In contrast, significant differences were found across land uses in the Mediterranean biome for the total abundance of individuals $\left(\chi_{5,13}^{2}=83.0, \mathrm{P}<0.001\right)$, species richness $\left(\chi_{5,13}^{2}=58.7, \mathrm{P}<0.001\right)$, Simpson's diversity index $\left(\chi_{5,12}^{2}=38.0, \mathrm{P}<0.001\right)$ and Berger-Parker dominance index $\left(\chi_{5,11}^{2}=25.7, \mathrm{P}<0.001\right)$. Total abundance and species richness declined very markedly in all land uses relative to primary vegetation (Fig. 3a, b). Surprisingly, secondary vegetation differed greatly from 
(a)

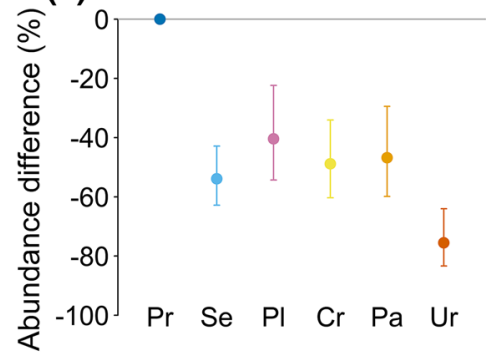

(c)

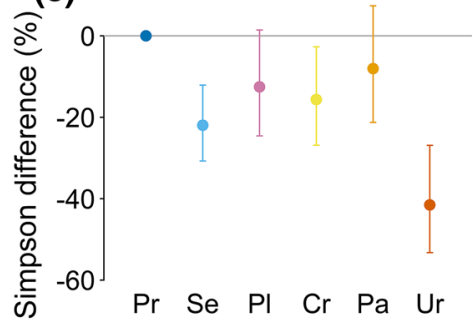

(b)

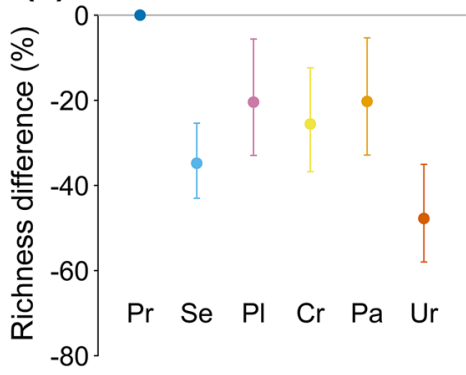

(d)

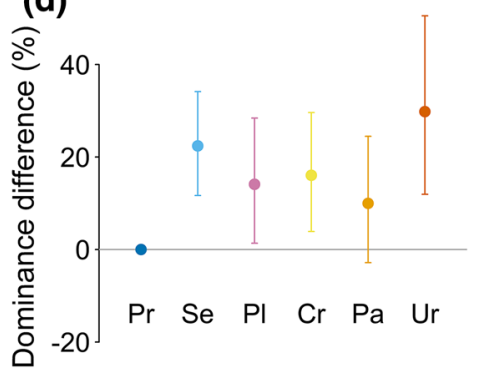

Fig. 3 Differences in the total abundance of individuals (a), species richness (b), Simpson's diversity index (c) and Berger-Parker dominance index (d) across land uses in Mediterranean environments, with primary vegetation as the reference condition. All tests yielded significant differences across land uses $(\mathrm{P}<0.001)$. Error bars represent $95 \%$ confidence intervals. $\mathrm{Pr}=$ Primary Vegetation, Se=Secondary Vegetation, $\mathrm{Pl}=$ Plantation forest, $\mathrm{Cr}=$ Cropland, $\mathrm{Pa}=$ Pasture, $\mathrm{Ur}=\mathrm{Urban}$

primary sites: after urban habitats, they yielded the lowest abundance, species richness and diversity (Simpson's index; Fig. 3a-c), and the highest dominance levels (Berger-Parker index; Fig. 3d). Plantation forests (including permanent crops that are important commercially in Mediterranean environments such as fruit and olives), herbaceous croplands and pastures had slightly higher biodiversity on average than secondary vegetation and urban areas. Significant spatial autocorrelation was detected in the residuals of the species richness model (Moran's I test: $\mathrm{I}=1.84, \mathrm{P}=0.03$ ), but not in the models of the other biodiversity measures $(\mathrm{P}>0.05)$.

\section{Endemism and species' identity}

The community-average geographical range occupancy of species did not vary significantly across land uses in drylands $\left(\chi_{2,11}^{2}=0.87, \mathrm{P}=0.65\right)$, although it did tend to increase in human-disturbed land uses (Fig. 5b). In contrast, there was a strong effect of land use on community-average geographical range occupancy in Mediterranean environments $\left(\chi_{3,7}^{2}=46.8, \mathrm{P}<0.001\right)$. In the Mediterranean biome, primary vegetation hosted the highest endemism rates (i.e. lowest average geographical ranges), with all other land uses (secondary vegetation, agriculture and plantation forests) containing communities with average range sizes approximately $75 \%$ higher (Fig. 5a). When compared to the variation in endemism between land uses globally across all terrestrial biomes (Fig. 5c; Newbold et al. 2018), Mediterranean environments stand out as having a substantially greater difference 

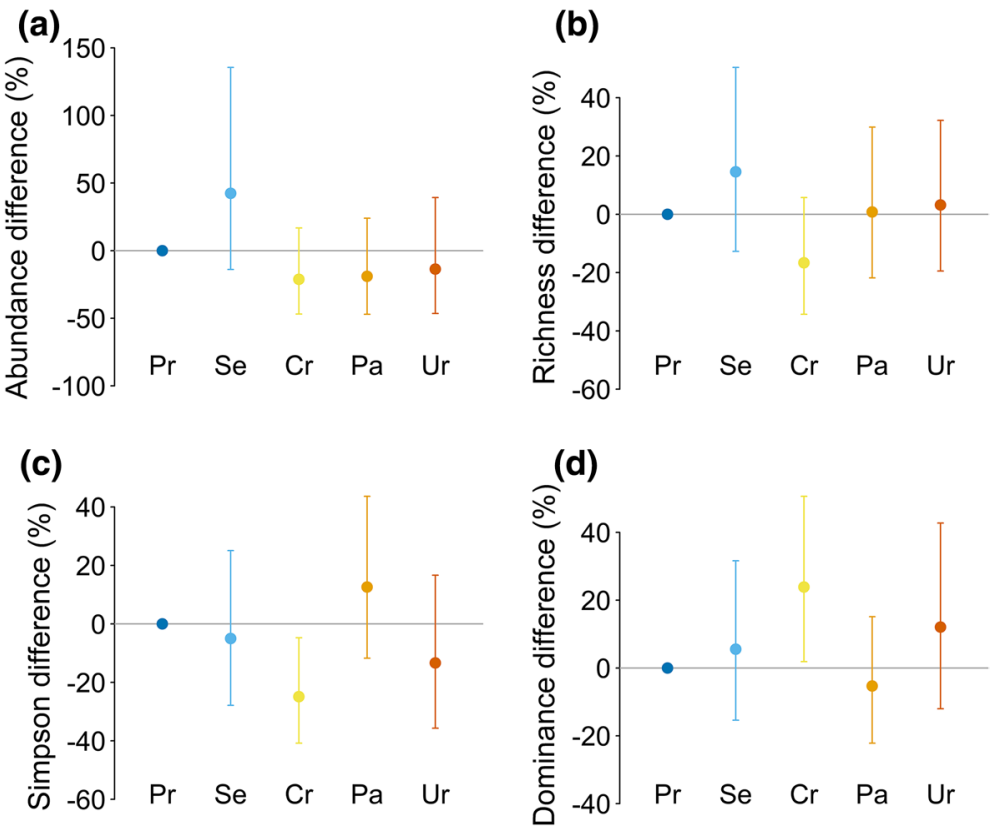

Fig. 4 Differences in the abundance of individuals (a), species richness (b), Simpson's diversity index (c) and Berger-Parker dominance index (d) across land uses in drylands, with primary vegetation as the reference condition. All tests yielded non-significant overall differences across land uses $(\mathrm{P}>0.09)$. Error bars represent $95 \%$ confidence intervals. $\mathrm{Pr}=$ Primary Vegetation, $\mathrm{Se}=$ Secondary Vegetation, $\mathrm{Pl}=\mathrm{Plantation}$ forest, $\mathrm{Cr}=$ Cropland, $\mathrm{Pa}=$ Pasture, $\mathrm{Ur}=\mathrm{Urban}$

Table 2 Average species compositional dissimilarity (1-Sørensen's index) of pairs of communities within and across different land uses in dryland and Mediterranean environments

\begin{tabular}{llll}
\hline Land use & Primary & Secondary & Agriculture \\
\hline Drylands & & & \\
Primary/secondary & $0.00(\mathrm{n}=13)$ & & $0.21(\mathrm{n}=8)$ \\
Agriculture & $0.21(\mathrm{n}=8)$ & & $-0.30(\mathrm{n}=8)$ \\
Mediterranean & & & \\
Primary & $0.00(\mathrm{n}=24)$ & $0.37(\mathrm{n}=6)$ & $0.11(\mathrm{n}=8)$ \\
Secondary & $0.37(\mathrm{n}=6)$ & $0.16(\mathrm{n}=6)$ & NA $(\mathrm{n}=0)$ \\
Agriculture & $0.11(\mathrm{n}=8)$ & NA $(\mathrm{n}=0)$ & $-0.02(\mathrm{n}=8)$
\end{tabular}

We grouped primary and secondary sites in the drylands analysis, owing to low representation. The number of published studies on which each value is based is given in parentheses

between land uses (an approximately 25\% greater difference between primary vegetation and all other land uses).

In dryland environments, the species community composition differed more strongly between natural and agricultural sites than within these land uses, and communities were found to be more similar within agricultural habitats than within natural habitats (Table 2). In Mediterranean environments, communities in secondary vegetation and, to a lesser extent, agricultural habitats differed more substantially from those in primary vegetation than communities within primary vegetation differed from each other (Table 2). 


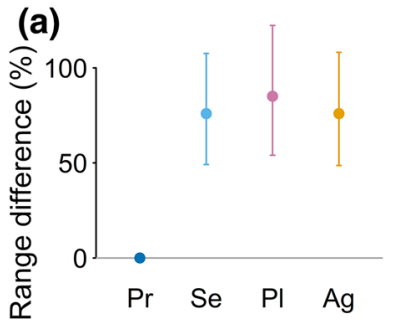

(b)

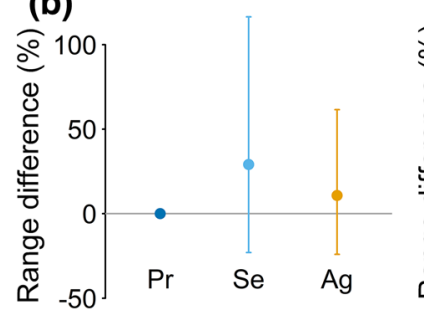

(c)

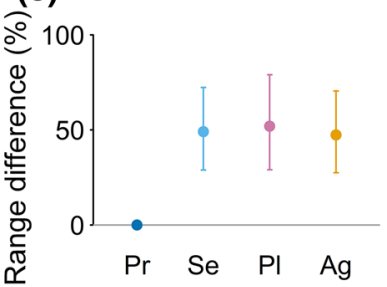

Fig. 5 Differences in community-average range sizes of species (Newbold et al. 2018) across land uses in Mediterranean environments (a), drylands (b) and globally across the world's biomes (c). Communities composed of species with large range sizes on average are communities with low endemism levels. The Mediterranean model yielded significant differences in average range size across land uses $(\mathrm{P}<0.001)$, while differences for drylands were non-significant $(\mathrm{P}=0.65)$. Error bars represent $95 \%$ confidence intervals. $\mathrm{Pr}=$ Primary Vegetation, $\mathrm{Se}=$ Secondary Vegetation, $\mathrm{Pl}=$ Plantation forest, $\mathrm{Cr}=\mathrm{Cropland}, \mathrm{Pa}=\mathrm{Pas}-$ ture, $\mathrm{Ur}=\mathrm{Urban}$

Communities within secondary vegetation differed strongly from one another, with intermediate self-similarity within primary vegetation, and the highest self-similarity in agriculture (Table 2). In Table 2, a lower compositional dissimilarity value indicates a higher similarity between the species communities of the compared habitats. Self-similarities between pairs of natural habitat sites for drylands and between pairs of primary vegetation sites for Mediterranean environments are the references to which the other comparisons are made (and are thus given a value of zero). Negative values are possible if the average pair of sites in a given combination of land uses are more self-similar compositionally than pairs of sites both in natural habitat (primary and secondary vegetation combined in drylands, or primary vegetation only in Mediterranean environments). In other words, we found that agricultural sites in both Mediterranean and dryland environments are more self-similar compositionally than natural-habitat sites.

\section{Discussion}

Land use is currently the strongest driver of biodiversity loss worldwide, and its influence will likely increase in future (Sala et al. 2000; Newbold et al. 2015). While the impacts of land use on biodiversity are often assumed to be consistent globally (Sala et al. 2000; Newbold et al. 2015), they can vary significantly across biomes. This study is the first, to our knowledge, to assess land-use impacts for dryland and Mediterranean biomes across the globe. Our results provide a few insights into the response of drylands' biodiversity, while highlighting a need for further research in this biome. We found clear, strong responses to land use of several metrics of biodiversity in Mediterranean ecosystems, which should inform future conservation measures.

\section{Drylands}

We found no significant differences in abundance or diversity across land uses in drylands, although croplands tended to have slightly lower biodiversity than natural habitat. Although the overall weak differences observed may be at least in part due to the low representation of this biome in the database, other studies using the PREDICTS 
database have found significant results in similar models with smaller sample sizes (e.g. Echeverría-Londoño et al. 2016). One previous study, in the shortgrass steppe of North America, found strong differences in responses among different groups of species, from abundance declines of over 50\% to increases of over 40\% (Milchunas et al. 1998). Future synthetic studies like ours should test for such taxonomic variation in responses, but for dryland environments this will require the collection of much more primary data.

A previous meta-analysis (Darkoh 2003) found that agriculture in the African drylands had lower species diversity and abundance than natural environments. This is contrary to our expectations, since in drylands agricultural areas have higher productivity and water availability than natural habitat (Webb et al. 1978). Darkoh (2003) identified harmful agricultural practices promoting the degradation of lands and vegetation as the root cause of this species decline. The impacts of agriculture on drylands' biodiversity may therefore vary greatly depending on the type of agriculture practiced. Ecological desert farming, including organic methods, intercropping, and conservation agriculture practices (García-Palacios et al. 2019), may increase some measures of biodiversity (Norfolk et al. 2013), by increasing productivity and water availability, among others, while avoiding the harmful effects of industrial agricultural practices. The impacts of different types of agriculture on biodiversity have been compared across biomes (Batáry et al. 2011), but remain to be assessed in drylands specifically. We obtained insufficient data to consider the intensity of agriculture within our models. However, at least for cropland, intensity was on average much lower for the sampled dryland sites than for the Mediterranean sites (Supplementary Table 1). While this may reflect a true general tendency for desert agriculture to be of lower intensity, it suggests that any intensification of dryland agriculture in future may cause greater losses of biodiversity than have been observed so far. Future studies could test the potentials of agro-ecological approaches in maintaining drylands' biodiversity.

Contrary to expectations, the endemicity of communities also did not vary across land uses, possibly due to sample sizes being further limited in this analysis compared with the analyses of the other biodiversity metrics, because of the need also to have range-size measures for the sampled species. We expected endemicity to be lower in agricultural areas than in natural habitat, as specialist species adapted to the harsh xeric conditions of deserts are particularly vulnerable to environmental changes such as those imposed by human modification (e.g. irrigation, vegetative cover) (Harrison and Noss 2017). There was nevertheless a marked shift in the species composition of communities between natural and agricultural sites, consistent with previous results focused on deserts in the Sinai Desert of Egypt (Norfolk et al. 2015). By driving community compositional shifts, the agricultural conversion of lands may consequently alter the ecosystem functions of dryland ecosystems (Symstad et al. 1998). Agricultural habitats also supported a more homogeneous species composition across sites (i.e. beta diversity) than natural environments, which may also have effects on ecosystem functioning (Wang and Loreau 2014).

Given the strong turnover in species composition that we show between natural and disturbed land uses in drylands, in order to maintain natural biodiversity and ecosystem function, conservation measures should prioritize natural habitats. More studies need to be conducted in drylands in order to determine with more confidence whether diversity and abundance differ across land uses. It is important to determine how biodiversity is changing in drylands and the consequence of these changes for ecosystem functioning, given the great human demographic importance of dryland environments (United Nations Environment Management Group 2011). 


\section{Mediterranean environments}

Previous studies have suggested large impacts of land use on the abundance and richness of Mediterranean communities worldwide, based on the large extent of human land use in this biome (Newbold et al. 2016a). However, these models did not consider that biodiversity within Mediterranean environments may be more or less sensitive to human land use than in other biomes. Our results suggest a disproportionate sensitivity of Mediterranean biodiversity to human land use, which means that losses of biodiversity are likely to have been even greater than reported previously (Newbold et al. 2016a). Even in secondary vegetation (natural habitat recovering after past disturbance), biodiversity was substantially lower than in primary vegetation, highlighting the irreplaceability of primary Mediterranean habitat. Previous cross-biome studies have produced mixed results regarding the biodiversity value of secondary vegetation. A global study using the same database that we used found reductions of $15-20 \%$ of species richness and $10-15 \%$ of total organism abundance in secondary vegetation in the earliest stages of recovery, while biodiversity showed little change or even an increase in more mature secondary vegetation (Newbold et al. 2015). In contrast, we found declines of more than $30 \%$ of species richness and more than $50 \%$ of abundance. Our results were very similar to the declines associated with secondary vegetation in another global study (Moreno-Mateos et al. 2017). However, this latter study considered mostly secondary vegetation in an early stage of recovery (averages of 16-22 years since the onset of recovery), whereas our Mediterranean secondary vegetation sites covered all stages of recovery (Supplementary Fig. 1).

Farmland abandonment is one of the commonest sources of current secondary vegetation in Mediterranean environments (Moreira and Russo 2007). As these lands become covered with forests, open areas and scrublands are lost, resulting in a shift in the species community and an overall species loss. Additionally, the accumulation of fuel in these abandoned lands makes them highly prone to wildfires. The large fires that characterise the Mediterranean further reduce biodiversity through landscape homogenization (Moreira and Russo 2007). Moreover, current endemism rates are highly influenced by past land uses in this biome, and are lowest where there used to be intense agricultural or urban uses (Lavergne et al. 2005). Past land uses, succession from abandoned farmlands and large wildfires may hence explain the remarkably low diversity, abundance and endemism levels, and the distinct composition of the species communities found in Mediterranean secondary vegetation. A limitation of our coarse-scale analysis is that we did not account for succession age and vegetation type, as information on these factors was not available for most secondary sites (Supplementary Fig. 1, Table 2).

Overall, our results suggest that conservation measures in Mediterranean ecosystems should prioritize the maintainenance of intact primary vegetation, which consistently supports a much larger and diverse community of species, with a greater proportion of more endemic species.

\section{Conclusions}

This study provides new insights into the effects of land use on biodiversity, in dryland and Mediterranean environments around the world. Our results may provide useful information for conservation measures in these biomes. The biodiversity in Mediterranean 
environments is more sensitive to land use than in drylands, and across all biomes considered together. Nevertheless, the shifts in species composition in anthropogenic land uses compared with natural habitats are likely to alter ecosystem functionality in both environments. The additional habitat conversion expected to take place in Mediterranean and dryland environments (Sala et al. 2000) is likely to be associated with large changes in biodiversity, which will be underestimated by models that ignore variation in biodiversity responses among biomes (Newbold et al. 2015, 2016a). Further research must be conducted in dryland environments to collect enough data to infer with confidence the biodiversity trends in this extensive and growing biome. However, our results suggest that conservation in both Mediterranean and dryland environments should focus on the preservation of intact primary habitat to maintain the natural composition of species.

Acknowledgements This study was made possible by the numerous researchers that contributed and collated the data in the PREDICTS database. This PREDICTS Project was supported by the UK Natural Environment Research Council (grant numbers: NE/J011193/2). Tim Newbold is also supported by a Royal Society University Research Fellowship (UF150526) and a grant from the Leverhulme Trust (RPG-2015-073).

Data availability The complete database used is available to download here: Species-level data - https://doi. org/10.6084/m9.figshare.7584431, Site-level data - https://doi.org/10.6084/m9.figshare.7584446.

Open Access This article is distributed under the terms of the Creative Commons Attribution 4.0 International License (http://creativecommons.org/licenses/by/4.0/), which permits unrestricted use, distribution, and reproduction in any medium, provided you give appropriate credit to the original author(s) and the source, provide a link to the Creative Commons license, and indicate if changes were made.

\section{References}

Batáry P, Báldi A, Kleijn D, Tscharntke T (2011) Landscape-moderated biodiversity effects of agri-environmental management: a meta-analysis. Proc R Soc Lond Ser B 278:1894-1902. https://doi.org/10.1098/ rspb.2010.1923

Bates D, Mächler M, Bolker B, Walker S (2015) Fitting linear mixed-effects models using \{lme4\}. J Stat Softw 67:1-48. https://doi.org/10.18637/jss.v067.i01

Boyce RL, Ellison PC (2001) Choosing the best similarity index when performing fuzzy set ordination on binary data. J Veg Sci 12:711-720. https://doi.org/10.2307/3236912

Cardinale BJ, Duffy JE, Gonzalez A et al (2012) Biodiversity loss and its impact on humanity. Nature 486:59-67. https://doi.org/10.1038/nature11148

Caruso T, Pigino G, Bernini F et al (2006) The Berger-Parker index as an effective tool for monitoring the biodiversity of disturbed soils: a case study on Mediterranean oribatid (Acari: Oribatida) assemblages. Biodiversity and conservation in Europe. Springer, Dordrecht, pp 35-43

Ceballos G, Ehrlich PR, Barnosky AD et al (2015) Accelerated modern human-induced species losses: entering the sixth mass extinction. Sci Adv 1:e1400253. https://doi.org/10.1126/sciadv.1400253

Cody M (1986) Diversity, rarity, and conservation in Mediterranean-climate regions. In: Soulé ME (ed) Conservation biology: the science of scarcity and diversity. Sinauer Associate, Sunderland, pp 122-152

Cowling RM, Rundel PW, Lamont BB et al (1996) Plant diversity in mediterranean-climate regions. Trends Ecol Evol 11:362-366

Darkoh MBK (2003) Regional perspectives on agriculture and biodiversity in the drylands of Africa. J Arid Environ 54:261-279. https://doi.org/10.1006/jare.2002.1089

Di Falco S (2012) On the value of agricultural biodiversity. Annu Rev Resour Econ 4:207-223. https://doi. org/10.1146/annurev-resource-110811-114543

Dornelas M, Gotelli NJ, McGill B et al (2014) Assemblage time series reveal biodiversity change but not systematic loss. Science 344:296-299. https://doi.org/10.1126/science.1248484

Echeverría-Londoño S, Newbold T, Hudson LN et al (2016) Modelling and projecting the response of local assemblage composition to land use change across Colombia. Divers Distrib 22:1099-1111. https:// doi.org/10.1111/ddi.12478 
Eldridge DJ, Poore AGB, Ruiz-Colmenero M et al (2015) Ecosystem structure, function and composition in rangelands are negatively affected by livestock grazing. Ecol Appl 26:1273-1283. https://doi. org/10.1890/15-1234.1

Ellis EC, Ramankutty N (2008) Putting people in the map: anthropogenic biomes of the world. Front Ecol Environ 6:439-447. https://doi.org/10.1890/070062

Falcucci A, Maiorano L, Boitani L (2007) Changes in land-use/land-cover patterns in Italy and their implications for biodiversity conservation. Landsc Ecol 22:617-631. https://doi.org/10.1007/s1098 0-006-9056-4

García-Palacios P, Alarcón MR, Tenorio JL et al (2019) Ecological intensification of agriculture in drylands. J Arid Environ 167:101-105. https://doi.org/10.1016/j.jaridenv.2019.04.014

Geeson NA, Brandt CJ, Thornes JB (eds) (2002) Mediterranean desertification: a network of processes and responses. John Wiley \& Sons, Chichester

Harrison S, Noss R (2017) Endemism hotspots are linked to stable climatic refugia. Ann Bot 119:207214. https://doi.org/10.1093/aob/mcw248

Hijmans RJ (2017) Raster: geographic data analysis and modeling

Hijmans RJ, Cameron SE, Parra JL et al (2005) Very high resolution interpolated climate surfaces for global land areas. Int J Climatol 25:1965-1978. https://doi.org/10.1002/joc.1276

Hillebrand H, Blasius B, Borer ET et al (2018) Biodiversity change is uncoupled from species richness trends: consequences for conservation and monitoring. J Appl Ecol 55:169-184. https://doi. org/10.1111/1365-2664.12959

Hudson LN, Newbold T, Contu S et al (2014) The PREDICTS database: a global database of how local terrestrial biodiversity responds to human impacts. Ecol Evol 4:4701-4735. https://doi. org/10.1002/ece3.1303

Hudson LN, Newbold T, Contu S, et al (2016) Dataset: the 2016 release of the PREDICTS database

Hudson LN, Newbold T, Contu S et al (2017) The database of the PREDICTS (Projecting Responses of Ecological Diversity In Changing Terrestrial Systems) project. Ecol Evol 7:145-188. https://doi. org/10.1002/ece3.2579

Kröger M (2014) The political economy of global tree plantation expansion: a review. J Peasant Stud 41:235-261. https://doi.org/10.1080/03066150.2014.890596

Lal R (2004) Soil carbon sequestration to mitigate climate change. Geoderma 123:1-22. https://doi. org/10.1016/j.geoderma.2004.01.032

Lavergne S, Thuiller W, Molina J, Debussche M (2005) Environmental and human factors influencing rare plant local occurrence, extinction and persistence: a 115-year study in the Mediterranean region. J Biogeogr 32:799-811. https://doi.org/10.1111/j.1365-2699.2005.01207.x

Maestre FT, Quero JL, Gotelli NJ et al (2012) Plant species richness and ecosystem multifunctionality in global drylands. Science 335:214-218. https://doi.org/10.1126/science.1215442

Mantyka-Pringle CS, Martin TG, Rhodes JR (2012) Interactions between climate and habitat loss effects on biodiversity: a systematic review and meta-analysis. Glob Chang Biol 18:1239-1252. https:// doi.org/10.1111/j.1365-2486.2011.02593.x

McIntyre NE, Rango J, Fagan WF, Faeth SH (2001) Group arthropod community structure in a heterogeneous urban environment. Landsc Urban Plan 52:257-274

Milchunas DG, Lauenroth WK, Burke IC (1998) Livestock grazing: animal and plant biodiversity of shortgrass steppe and the relationship to ecosystem function. Oikos 83:65-74. https://doi. $\operatorname{org} / 10.2307 / 3546547$

Moore D, Brooks N, Cranston G, Galli A (2010) The future of the Mediterranean: tracking ecological footprint trends-interim report. Oakland, CA

Moreira F, Russo D (2007) Modelling the impact of agricultural abandonment and wildfires on vertebrate diversity in Mediterranean Europe. Landsc Ecol 22:1461-1476. https://doi.org/10.1007/s1098 0-007-9125-3

Moreno-Mateos D, Barbier EB, Jones PC et al (2017) Anthropogenic ecosystem disturbance and the recovery debt. Nat Commun 8:14163. https://doi.org/10.1038/ncomms14163

Myers N, Mittermeier RA, Mittermeier CG et al (2000) Biodiversity hotspots for conservation priorities. Nature 403:853-858. https://doi.org/10.1038/35002501

Newbold T, Hudson LN, Phillips HRP et al (2014) A global model of the response of tropical and subtropical forest biodiversity to anthropogenic pressures. Proc R Soc Lond Ser B 281:20141371

Newbold T, Hudson LN, Hill SLL et al (2015) Global effects of land use on local terrestrial biodiversity. Nature 520:45-50. https://doi.org/10.1038/nature14324

Newbold T, Hudson LN, Arnell AP et al (2016a) Has land use pushed terrestrial biodiversity beyond the planetary boundary? A global assessment. Science 353:288-291 
Newbold T, Hudson LN, Hill SLL et al (2016b) Global patterns of terrestrial assemblage turnover within and among land uses. Ecography 39:1151-1163. https://doi.org/10.1111/ecog.01932

Newbold T, Hudson LN, Contu S et al (2018) Widespread winners and narrow-ranged losers: land use homogenizes biodiversity in local assemblages worldwide. PLoS Biol 16:e2006841. https://doi. org/10.1371/journal.pbio.2006841

Norfolk O, Eichhorn MP, Gilbert F (2013) Traditional agricultural gardens conserve wild plants and functional richness in arid South Sinai. Basic Appl Ecol 14:659-669. https://doi.org/10.1016/j. baae.2013.10.004

Norfolk O, Eichhorn MP, Gilbert FS (2015) Contrasting patterns of turnover between plants, pollinators and their interactions. Divers Distrib 21:405-415. https://doi.org/10.1111/ddi.12295

Olson DM, Dinerstein E, Abell R et al (2000) The Global 200: a representation approach to conserving the Earth's distinctive ecoregions. Conservation Science Program, WWF-US, Washington, DC

Phillips HRP, Newbold T, Purvis A (2017) Land-use effects on local biodiversity in tropical forests vary between continents. Biodivers Conserv 26:2251-2270. https://doi.org/10.1007/s10531-017-1356-2

Rigby RA, Stasinopoulos DM, Akantziliotou C (2008) A framework for modelling overdispersed count data, including the Poisson-shifted generalized inverse Gaussian distribution. Comput Stat Data Anal 53:381-393. https://doi.org/10.1016/j.csda.2008.07.043

Sala OE, Chapin FS III, Armesto JJ et al (2000) Global biodiversity scenarios for the year 2100. Science 287:1770-1774. https://doi.org/10.1126/science.287.5459.1770

Seto KC, Fragkias M, Güneralp B, Reilly MK (2011) A meta-analysis of global urban land expansion. PLoS ONE 6:e23777. https://doi.org/10.1371/journal.pone.0023777

Somerfield PJ, Clarke KR, Warwick RM (2008) Simpson index. Encyclopedia of ecology, 2nd edn. Elsevier, Oxford, pp 3252-3255

Steffen W, Broadgate W, Deutsch L et al (2015) The trajectory of the Anthropocene: the great acceleration. Anthr Rev 2:81-98. https://doi.org/10.1177/2053019614564785

Symstad AJ, Tilman D, Willson J, Knops JMH (1998) Species loss and ecosystem functioning: effects of species identity and community composition. Oikos 81:389-397

R Core Team (2016) R: a language and environment for statistical computing

The Food and Agriculture Organization of the United Nations (2016) Trees, forests and land use in drylands: the first global assessment. Rome

The Nature Conservancy (2009) Conservation GIS data. http://maps.tnc.org/gis_data.html. Accessed 2 Jul 2019

The World Bank (2017) Agricultural land (\% of land area). https://data.worldbank.org/indicator/AG.LND. AGRI.ZS. Accessed 16 Oct 2018

Underwood EC, Viers JH, Klausmeyer KR et al (2009) Threats and biodiversity in the mediterranean biome. Divers Distrib. https://doi.org/10.1111/j.1472-4642.2008.00518.x

United Nations Environment Management Group (2011) Global drylands: a UN-wide response. UN Environment Management Group, Châtelaine

Von Lampe M, Willenbockel D, Ahammad H et al (2014) Why do global long-term scenarios for agriculture differ? An overview of the AgMIP global economic model intercomparison. Agric Econ 45:3-20. https://doi.org/10.1111/agec.12086

Wang S, Loreau M (2014) Ecosystem stability in space: $\alpha, \beta$ and $\gamma$ variability. Ecol Lett 17:891-901. https:// doi.org/10.1111/ele.12292

Webb W, Szarek S, Lauenroth W et al (1978) Primary productivity and water use in native forest, grassland, and desert ecosystems. Ecology 59:1239-1247

Zuur AF, Ieno EN, Walker NJ et al (2009) Mixed effects models and extensions in ecology with R. Springer, New York

Publisher's Note Springer Nature remains neutral with regard to jurisdictional claims in published maps and institutional affiliations. 